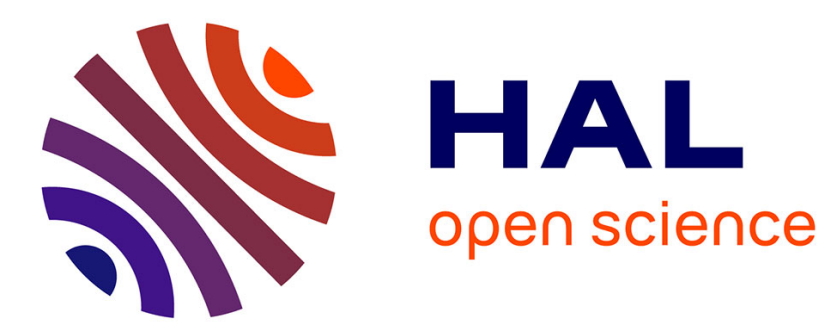

\title{
Charge transport in oxygen-doped polysilicon layers on Si
}

\author{
J.F. Verwey, W. Ruis, I. Sens
}

\section{To cite this version:}

J.F. Verwey, W. Ruis, I. Sens. Charge transport in oxygen-doped polysilicon layers on Si. Revue de Physique Appliquée, 1978, 13 (12), pp.821-824. 10.1051/rphysap:019780013012082100 . jpa00244553

\section{HAL Id: jpa-00244553 https://hal.science/jpa-00244553}

Submitted on 1 Jan 1978

HAL is a multi-disciplinary open access archive for the deposit and dissemination of scientific research documents, whether they are published or not. The documents may come from teaching and research institutions in France or abroad, or from public or private research centers.
L'archive ouverte pluridisciplinaire HAL, est destinée au dépôt et à la diffusion de documents scientifiques de niveau recherche, publiés ou non, émanant des établissements d'enseignement et de recherche français ou étrangers, des laboratoires publics ou privés. 


\title{
PASSIVATION.
}

\section{CHARGE TRANSPORT IN OXYGEN-DOPED POLYSILICON LAYERS ON Si}

\author{
J. F. VERWEY, W. RUIS and I. SENS \\ Philips Research Laboratories Eindhoven, The Netherlands
}

\begin{abstract}
Résumé. - On montre que les couches minces de silicium polycristallin dopé avec de l'oxygène (polydox) peuvent être utilisées pour la passivation des jonctions p-n au-dessous des couches. Le mécanisme de la conduction est dérivé des mesures dans les couches minces déposées directement sur les cristaux de silicium. A la température ambiante on trouve une conduction Poole-Frenkel et à une température plus haute on a probablement une conduction par les sauts d'un piège localisé à l'autre.
\end{abstract}

Abstract. - It is shown that layers of polysilicon doped with oxygen (polydox) can be used for the passivation of underlying p-n junctions. The conduction mechanism was derived from measurements in layers directly deposited on to silicon crystals. At room temperature we found PooleFrenkel conduction changing at higher temperatures, presumably, to hopping in localized states.

1. How can polydox passivate p-n junctions ? Semi-insulating polysilicon (SIPOS) has been suggested for the passivation of $p-n$ junctions in silicon. Layers of polycristalline silicon were made semiinsulating by adding oxygen during growth [2]. We studied these layers grown at a reduced pressure. We call them polydox which stands for polysilicon doped with oxygen.

- Figures 1 and 2 are used to' demonstrate how polydox layers can passivate underlying $p-n$ junctions. Figure 1 shows a cross-section of a p-n junction near the $\mathrm{Si}_{-} \mathrm{SiO}_{2}$ interface. If positive charge is present in the $\mathrm{SiO}_{2}$ (indicated by crosses) then the depletion layer of the junction is constricted at the interface. Consequently, the breakdown voltage of the junction is lowered.

In figure 2 a slightly conducting layer of polydox is present between the charged oxide and the silicon crystal. In this case the charge in the oxide induces negative charge in the polydox layer and no constriction of the depletion layer takes place. So, the breakdown voltage of the underlying junction becomes insensitive to the amount of oxide charge. Then the

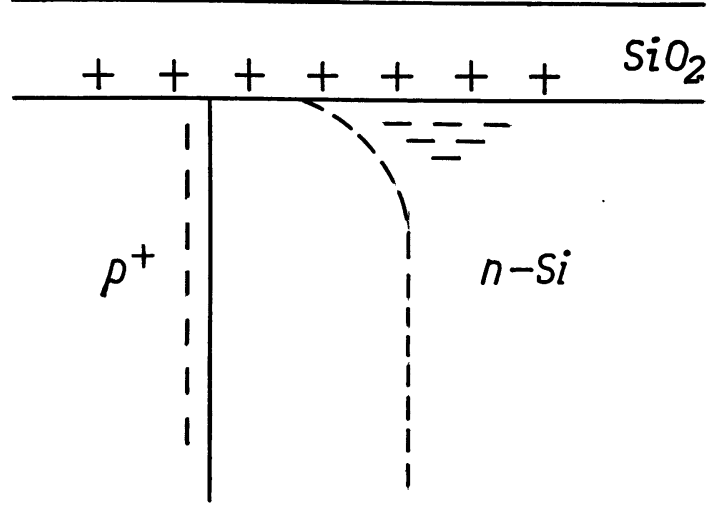

Fig. 1. - Cross-section of a $\mathrm{p}^{+}-\mathrm{n}$ junction covered by a charged $\mathrm{SiO}_{2}$ layer.

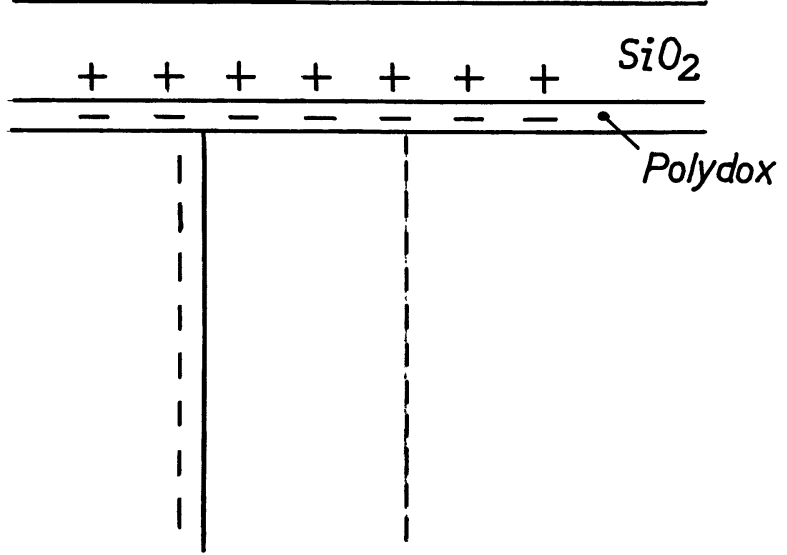

FIG. 2. - Cross-section of a $\mathrm{p}^{+}-\mathrm{n}$ junction with polydox between oxide and silicon.

junction is passivated for oxide charge and also for external fields, which have the same effect as a charge.

The influence of external fields on the breakdown voltage was studied in gated diodes. The result is shown in figure 3 . The polydox layer was grown at a pressure of 0.5 torr from a stream of $\mathrm{SiH}_{4}$ and $\mathrm{N}_{2} \mathrm{O}$ at a temperature of $650{ }^{\circ} \mathrm{C}$. The layer with a thickness of $0.5 \mu \mathrm{m}$ was coated with a $0.9 \mu \mathrm{m} \mathrm{SiO}_{2}$ layer by chemical vapour deposition. Figure 3 shows (curve 1) the breakdown voltage $V_{\mathrm{BV}}$ as a function of the voltage $V_{\mathrm{g}}$ applied to an $\mathrm{Al}$ electrode (gate) on top of the $\mathrm{SiO}_{2}$ layer above the place where the $\mathrm{p}$-n junction intersects the Si-polydox interface. Curve 2 shows $V_{\mathrm{BV}}$ of an identical junction without polydox. In the former case no effect of $V_{\mathrm{g}}$ can be seen, hence it can be concluded that good passivation against external fields is obtained.

For the passivation effect it is necessary to have polydox layers that are slightly conducting in order to induce variable amounts of charge in them. Therefore we studied the conduction in more detail. 


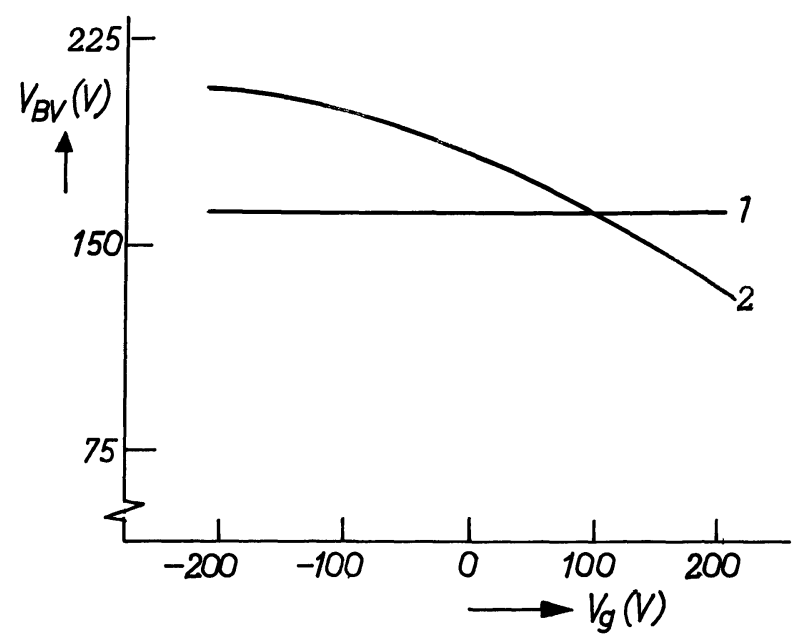

Fig. 3. - Breakdown voltage $V_{\mathrm{BV}}$ as a function of the gate voltage $V_{\mathrm{g}}$ of gated diodes with (curve 1) and without (curve 2) properly working polydox.

2. Conduction mechanism. - The conduction of the polydox layers was measured in the structure of figure 4. Usually this quantity is measured in layers on top of a relatively thick $\mathrm{SiO}_{2}$ layer in a direction parallel to the surface of the silicon crystal $[2,3]$. In our approach the conduction was measured in layers directly deposited onto the Si-crystal, as can be seen in figure 4 . This structure is better related to the use of polydox in practical devices where it is also directly deposited onto the silicon. The central $\mathrm{Al}$ dot in figure 4 has a diameter of $570 \mu \mathrm{m}$, the outer Al stripe is used for the reduction of the surface leakage current.

Figure 5 shows an example of current-voltage curves obtained in polydox layers. The current depends on the polarity of the voltage. The current indicated by $F$ in figure 5 is obtained with forward polarity. In this case the metal electrode on the polydox layer is positively biased with respect to an n-type substrate (or negatively biased with respect to a p-type substrate). The $\mathbf{R}$ in figure 5 indicates reverse bias, i.e. the opposite polarity. In this case a positive voltage on the metal electrode induces a depletion layer in a p-type substrate and a substantial voltage drop takes place accross it. In this way, the reverse current is smaller than the forward current.

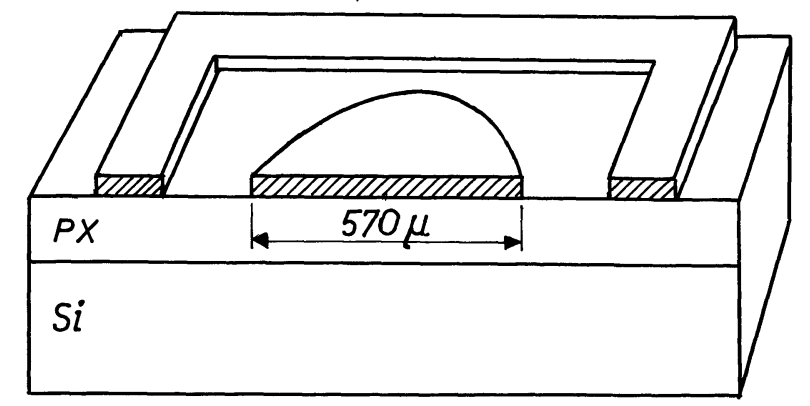

Fig. 4. - Cross-section of the structure used for conduction measurements of the polydox layers.

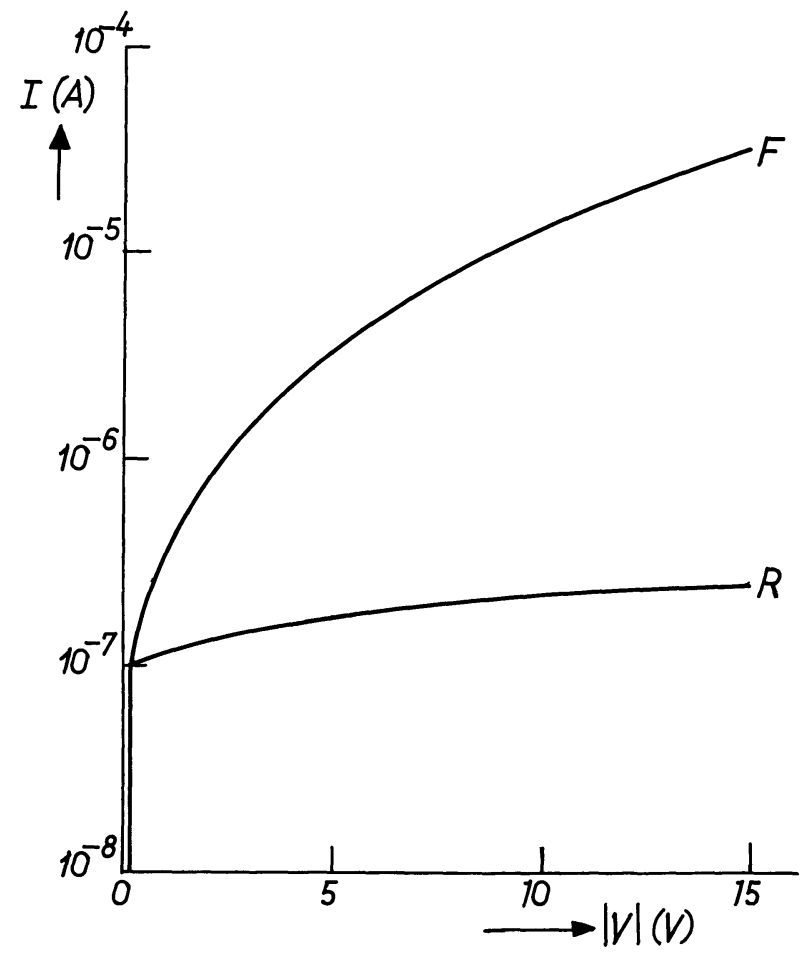

Fig. 5. - Current-voltage curves of a polydox layer. Curve F is the forward current (accumulation in Si). Curve R is the reverse current (depletion in $\mathrm{Si}$ ).

In polydox layers on highly doped substrates $\left(n^{+}\right.$-type) the forward and reverse currents are equal. Presumably, the charge carriers are then able to tunnel through the relatively thin depletion layer in the reverse current mode. Therefore, we conclude that the forward current is governed by processes in the bulk of the polydox. We studied the forward current in more detail in order to obtain information on the conduction mechanism in the polydox.

Figure 6 shows the forward current $I_{\mathrm{F}}$ as a function of voltage $V_{\mathrm{F}}$ in a double-logarithmic plot. In this figure we plotted two curves, one for excess current and the other for typical current. The excess current behaviour was measured in less than 5 per cent 'of the samples. Therefore, we may conclude that the excess current behaviour is due to residual inhomogeneities in the polydox layers. If the polydox layers were grown at atmospheric pressure then the excess current behaviour was dominant. The typical current behaviour in figure 6 is ascribed to the intrinsic conduction in homogeneous polydox and this is further analysed.

At relatively low fields the forward currents showed an ohmic region from which the resistivity can be calculated. At higher fields the current became nonohmic which is likely to be due to Poole-Frenkel conduction (see for instance ref. [4]). In this conduction mechanism the current is given by

$$
I_{\mathrm{F}} \sim \exp \beta^{\prime}\left(\frac{V_{\mathrm{F}}}{d}\right)^{1 / 2}
$$




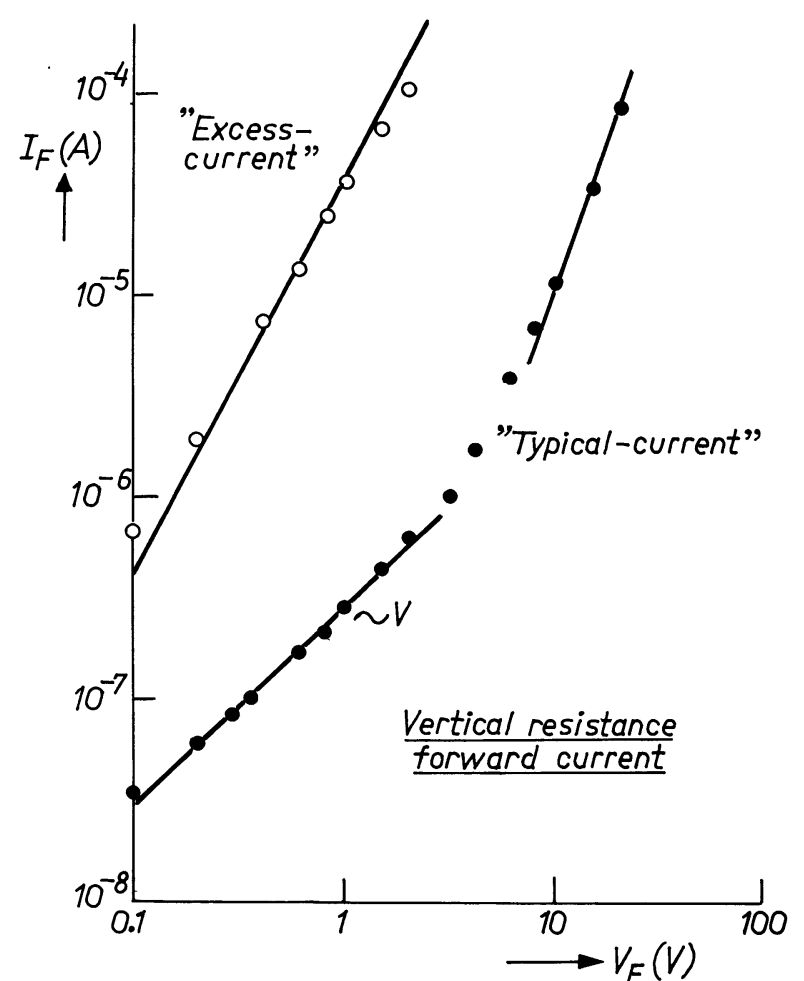

Fig. 6. - Forward current as function of the voltage of two samples on one wafer.

where $d$ is the thickness of the layer, $\beta^{\prime}$ is the PooleFrenkel constant,

$$
\beta^{\prime}=\left(\frac{q}{2 \pi \varepsilon}\right)^{1 / 2} \cdot(k T)^{-1},
$$

$q$ is the elementary charge, $\varepsilon$ is the permittivity, $k$ is Boltzmann's constant and $T$ is the temperature.

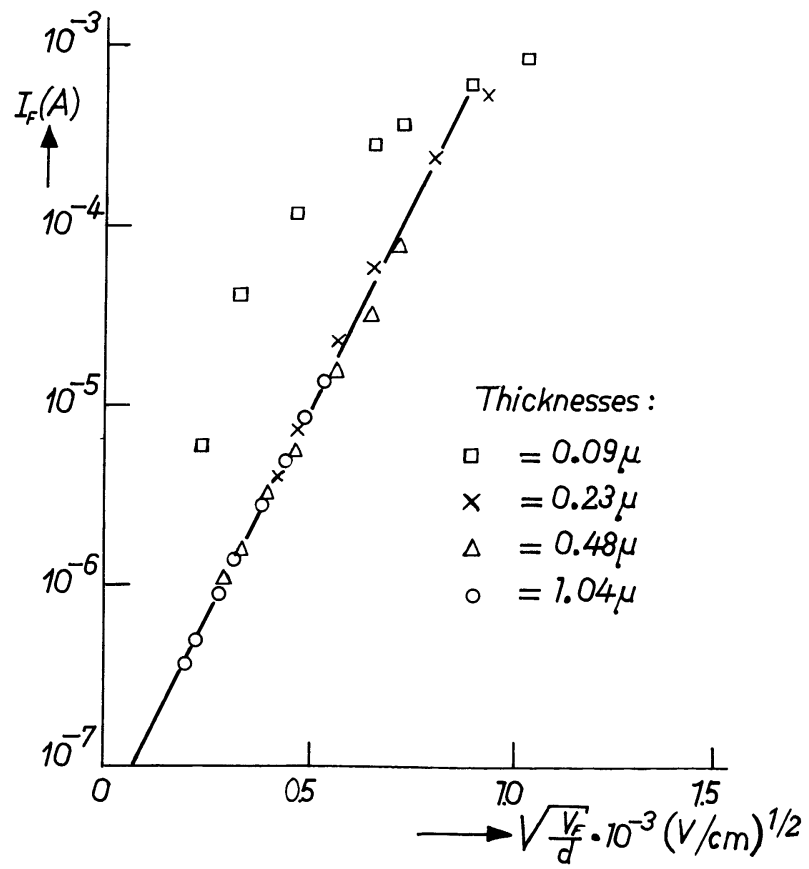

Fig. 7. - Poole-Frenkel plot of the forward current in polydox layers with different thicknesses.

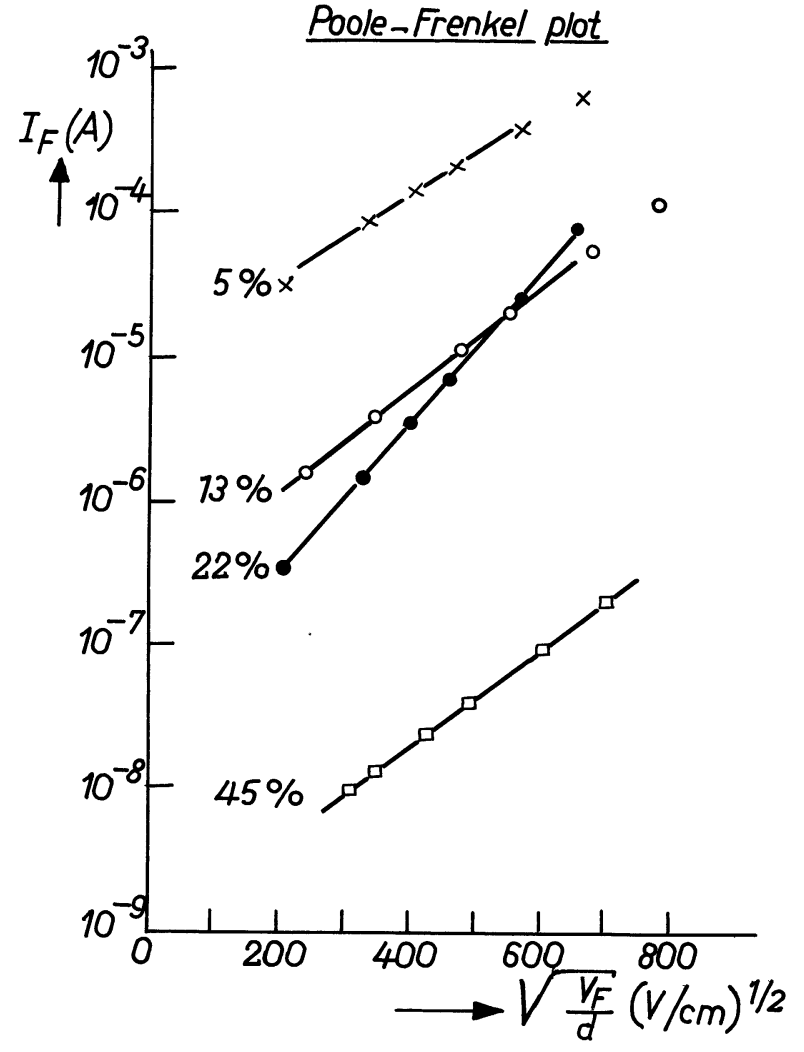

Fig. 8. - Poole-Frenkel plot of the forward current in polydox layers with different oxygen concentrations.

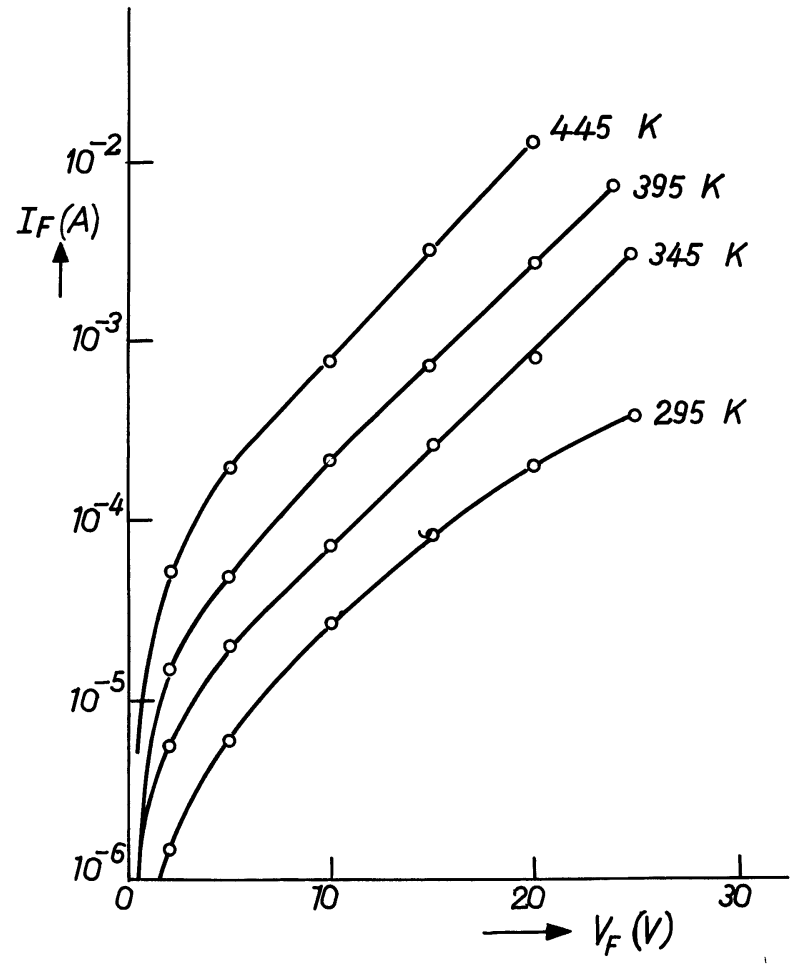

FIG. 9. - Forward current in polydox layers as function of the voltage for different temperatures. 
Figure 7 shows a Poole-Frenkel plot of the forward current in polydox layers with different thicknesses. One may observe that straight lines are obtained except for the thinnest layer. Presumably this layer is not sufficiently homogeneous. The results in figure 7 support a model of Poole-Frenkel conduction.

Figure 8 shows Poole-Frenkel plots for the forward current in layers with different oxygen concentrations. Again reasonably straight lines were obtained with a slope that was not very much dependent on oxygen concentration. From the value of the slopes we calculated a value for $\varepsilon$ that was between that of silicon and silicon dioxide. We found a relative dielectric constant of about 7 which 'may be compared with 3.9 and 11.7 for $\mathrm{SiO}_{2}$ and $\mathrm{Si}$ respectively.

Figure 9 shows the forward current for different temperatures. The curve for room temperature $(295 \mathrm{~K})$ was a straight line in a Poole-Frenkel plot but the curves for higher temperatures were not. Apparently they have a simple exponential relation with the applied voltage $V_{\mathrm{F}}$. Possibly, the voltage dependence must now be explained by hopping from one centre to the other (Ref. [3]). These centres are likely to be localized states in the forbidden band of the silicon (Ref. [3]).

\section{References}

[1] Matsushita, T., Aoki, T., Ohtsu, T., Yamoto, H., Yayashi, H., Okayama, M. and Kawana, Y., IEEE Trans. Electron Devices ED 23 (1976) 826.

[2] Mochizuki, H., Aoki, T., Yamoto, H., Okayama, M., Авe, M. and ANdo, T., Proc. 7th Conference Solid State Devices, Tokyo 1975, Suppl. Jpn. J. Appl. Phys. 15 (1976) 35.
[3] Hamasaki, M., Adachi, T., Wakayama, S. and KikUChi, M. Solid State Commun. 21 (1977) 591.

[4] LAMB, D. R., Electrical Conduction Mechanisms in Thin Insulating Films, Methuen, London, 1967. 